Research

\title{
The relations between symptoms, somatic and psychiatric conditions, life satisfaction and perceived health. A primary care based study
}

\author{
Ahmad Al-Windi*
}

Address: Family Medicine Stockholm, Karolinska Institute, Alfred Nobels allé 12, SE-141 83 Huddinge, Sweden

Email: Ahmad Al-Windi* - ahmad.al-windi@slpo.sll.se

* Corresponding author

Published: 27 April 2005

Received: 13 February 2005

Health and Quality of Life Outcomes 2005, 3:28 doi:10.1 186/1477-7525-3-28

Accepted: 27 April 2005

This article is available from: http://www.hqlo.com/content/3/1/28

(c) 2005 Al-Windi; licensee BioMed Central Ltd.

This is an Open Access article distributed under the terms of the Creative Commons Attribution License (http://creativecommons.org/licenses/by/2.0), which permits unrestricted use, distribution, and reproduction in any medium, provided the original work is properly cited.

\begin{abstract}
Background: In spite of the fact that self-rated health is such an important factor, little is known about the aetiological background to poor perceived health and also less is known about the impact of life satisfaction on health in a primary care practice population. The aim of this study was to evaluate the effect of socio-demographic characteristics, lifestyle factors, symptoms, somatic and psychiatric conditions as well as health status measures and life satisfaction on perceived health in a multi-ethnic Swedish health practice population.
\end{abstract}

Methods: Four-hundred and seventy adult patients, who visited the Jordbro Health Care Centre District $(\mathrm{JHC})$, Haninge Municipality, participated in this study. A general questionnaire with questions about socio-demographic characteristics, lifestyle, health status and chronic disease were used. In addition to that, the Primary Care Evaluation of Mental Disorders (PRIME-MD) was used. Furthermore, physical examinations were conducted. Unconditional logistic regression in successive models was used, adjusted for socio-demographic variables and other confounders.

Results: Life satisfaction is the strongest predictor of poor perceived health in addition to country of birth, number of symptoms and depression. Being born in Sweden or other Nordic countries were related to lower OR as compared to those born outside Europe. The OR for non-depressed vs. depressed was $0.29(0.17-0.48)$ and for non-symptomatic vs. symptomatic (I-3 symptoms) 0.25 $(0.46-0.48)$. The OR and $95 \% \mathrm{Cl}$ for low satisfaction with life was 15.40 (5.28-44.97) in comparison to those who are satisfied with life.

Conclusion: Country of birth, depression, number of symptoms and life satisfaction are factors related significantly and independently to perceived health. Life satisfaction is the strongest predictor of perceived poor health.

\section{Background}

During the past two decades, interest in subjects' per- ceived health has become one of the important research fields in epidemiology and research concerning health 
services [1-4]. At the beginning of the 1980s, Kaplan and others reported an association between subjects' perceived health and mortality [5-7]. Several other international studies later confirmed these findings. Follow-up studies have shown similar results - i.e., poor self-rated health as a strong predictor of mortality $[1,2,8]$. Self-assessment of health status appears to be a good measure of current physical health, morbidity, disability and a predictor of health care utilisation [6,9-17].

Numerous reports have shown a strong association between various indicators of individual socio-economic positions [18-24]. A strong correlation has also been found between self-reported health status and both socioeconomic status and increased risk of mortality for all ethnic groups [25]. In the United Kingdom a number of studies have found higher morbidity and mortality rates for most British ethnic minorities than in the white population [23,26-28]. A study from the United States observed that socio-economic status was a principal determinant of racial/ethnic disparities in health, but several other factors, for example, medical care, migration, stress and resources, also play a role [27]. However, the effect of ethnicity has been compared to social class [29].

It is evident that subjective health assessment is a valid indicator of health status in middle-aged populations, and that it can be used in cohort studies and monitoring of a population's health $[3,25]$. The use of socio-economic status has been recommended for screening of majority groups, but not for minority ones [30]. In spite of the fact that self-rated health is such an important factor, little is known about the aetiological background to poor perceived health and also less is known about the impact of life satisfaction on health in a primary care practice population. Palmore and Kivett reported in 1977 that life satisfaction at the end of a 4-year period was significantly related to initial levels of self-rated health among subjects aged $46-70$ years [31]. However, some other studies on the elderly show relations between perceived health and life satisfaction [32-34]. For example, Wang et al. found that life satisfaction was related to mental health both in females and males [32]. Benyamini et al. reported from a study of an old population (mean age 73) that both selfrated oral health and self-rated health independently explained a significant amount in concurrent rates of selfesteem and life satisfaction [33]. Ho et al. found that satisfaction was related to higher social class, education, good perceived health and other factors [34].

The present investigation is part of a comprehensive programme entitled "Improving Health Care in Jordbro (IHCJ)" to assess the influence of socio-demographic characteristics, including country of birth, as well as morbidity on health care and drug utilisation in patients resi- dent in Jordbro, a small multi-ethnic sub-community in Stockholm, Sweden. In this study we explore the relations between socio-demographic characteristics, lifestyle factors, somatic and psychiatric symptoms as well as health status measures and perceived health.

The aim of this study was to evaluate the effect of sociodemographic characteristics, lifestyle factors, symptoms, somatic and psychiatric conditions as well as health status measures, and life satisfaction on perceived health in a multi-ethnic Swedish health practice population. The Committee on Research Ethics at the School of Medicine, Karolinska Institute, approved the study.

\section{Methods \\ Subjects and setting}

A full description of the methodology is provided elsewhere [35]. The patient sample was recruited between October 2002 and April 2003 from adult patients $(\geq 16$ years old) presenting for routine visits at the Jordbro Health Care Centre (JHC). In total 470 adult patients who visited the JHC during the period participated in this study.

The JHC has a catchment area of 9500 patients and approximately 9000 patients are registered at the health centre. At the time of the study the proportion of patients $>15$ years old was $77 \%$, i.e. 7296 patients. The study population consists of patients who were registered consequently during the first four weeks of the study period and only six patients provided insufficient data, i. e. only six patients did not fulfil the survey completely. All adult patients ( $\geq 16$ years) who visited the health care centre were included but not the emergency cases.

The study consisted of three parts: (a) a general questionnaire $[35,36]$, (b) patient questionnaire (PQ) followed by a clinical interview [37] and (c) a medical examination.

a) The general questionnaire dealing with questions on socio-demographic characteristics, lifestyle, health status and medicine use was handed out to the patients. The socio-demographic variables included, in addition to age and gender, family situation (e.g. whether the patient lived alone, with another adult or with children) and country of birth. In addition to that, the questionnaire included questions on 16 common somatic diseases and one on whether the respondents perceived themselves to be healthy or not. They were also asked to indicate the degree of life satisfaction, perceived health and health status. Patients were asked to state whether they had any chronic disease.

b) The Primary Care Evaluation of Mental Disorders (PRIME-MD) questionnaire was used [37]. It is a two- 
stage process for diagnosing mental disorders by primary care physicians consisting of a patient questionnaire (PQ) as an initial screening followed by a structured clinical interview with a psychologist/physician, consisting of five diagnosing modules to further evaluate those groups of disorders whose presence had been indicated by positive answers to the initial questionnaire screening [37]. Psychiatric diagnoses were based on those listed in the Diagnostic and Statistical Manual of Mental Disorders, fourth edition (DSM-IV) [38]. A more detailed description of the PRIME-MD can be found in Loerch et al. [37].

c) Medical examination: this consisted of weight, height, and laboratory analyses including fasting blood glucose, serum cholesterol and serum triglycerides, flow volume spirometry and electrocardiography.

\section{Outcome variables}

Subjects were asked to indicate their present degree of perceived health on a seven-point scale, ranging from score 1 "very bad" to score 7 "excellent, could not be better". The variables were dichotomised to "Good scores" score 5-7 and "Bad or poor scores (PPH)" score 1-4.

\section{Explanatory variables}

The general questionnaire

The dichotomised or ordinal forms for these variables were used in nominal logistic regression - i.e., age was grouped into: 16-44, 45-64 and 65+. Gender: male and female. Working: yes and no. Country of birth: Sweden, other Nordic countries, Other European countries and rest of the world. Living conditions: the variables were: Living alone, Living with another adult and Living with children $<18$ years. The presence of diagnosis was regarded as "yes", 1 and the "absence" as no, 0. Reported health status: Healthy: yes, 1; no, 0 and in between or unsure, 2. Life satisfaction: was defined on a seven-point scale, ranging from score 1 "very bad" to score 7 "excellent, could not be better". The variables were dichotomised to "Good scores" score 5-7, "Fair 'scores 3-4 and "Bad or poor scores" score 1-2.

\section{Psychiatric evaluation}

The patient questionnaire (PQ) consisted of 28 yes/no questions about the presence of symptoms during the previous month, of which 15 were about somatic symptoms and the other about psychiatric symptoms and alcohol. Psychiatric diagnoses: mood disorders, anxiety, compulsive disorder, social phobia, probable alcohol abuse/dependence and eating disorders. The presence of diagnosis was regarded as "yes", 1, and the "absent" as no, 0.

\section{Medical Examination}

BMI: Weight in kilograms/(height in metres) ${ }^{2}$; blood pressure: systolic and diastolic; heart rate (pulse) during 1 minute; fasting blood glucose, serum cholesterol and triglycerides. Spirometry: mean values were calculated for vital capacity (VC), forced expiratory volume in 1 second (FEV1), Forced vital capacity (FVC) and peak expiratory flow (PEF). Electrocardiography: The results were judged and grouped in four categories: normal, not surely pathological, suspect pathological and pathological. Common somatic disease consisted of 16 common conditions and one general question on chronic disease. The presence of condition was regarded as "yes", 1 and the absent as "no", 0 .

\section{Statistical methods}

The data were analysed with the SAS and JMP software packages $[39,40]$. Standard methods were used to obtain summary statistics, such as means, prevalence and other measures. Chi-square test or Fisher's exact test were used to calculate the p-values. Associations between perceived health and the continuous independent variables age, life satisfaction, BMI, blood pressure, heart rate, blood glucose, serum triglycerides and cholesterol were estimated as product moment correlations according to Spearman. All tests were two-tailed. Probability (p-) values less than 0.05 was regarded as statistically significant.

We analysed the relationships between perceived health and the explanatory variables, using the unconditional logistic regression in a successive model, adjusted for socio-demographic variables and other confounders. The interaction terms for chronic disease ${ }^{*}$ depression, depression*symptoms and chronic disease* depression*symptoms were not significant.

The results are shown as odds ratios (OR) with 95\% confidence intervals (CIs). The fit of the models was judged by the Hosmer-Lemeshow goodness-of-fit test. The models were considered acceptable if $\mathrm{p}>0.05$ and all models met this criteria. The results are shown as odds ratios (OR) with 95\% confidence intervals (CIs).

\section{Results \\ Socio-demographic characteristics, self-health report, health status measures, life-satisfaction and perceived health}

Table 1 shows that $46.4 \%$ of respondents reported perceived poor health. All variables except living with or without children were significantly related to perceived health. A higher proportion of subjects aged 45-64 years reported poor health ( $\mathrm{PPH}$ ) as compared to younger subjects aged 16-44 years. The proportion of subjects reporting PPH is higher among females, subjects not working, subjects born outside Sweden, living alone and not living with another adult compared to males, working subjects, subjects born in Sweden, not living alone and living with another adult. A significantly higher proportion of 
Table I: Population distribution in per cent (\%) by perceived health and sociodemographic characteristics, reported health status and life satisfaction.

\begin{tabular}{|c|c|c|c|c|}
\hline \multirow[b]{2}{*}{ Variable } & & \multicolumn{3}{|c|}{ Perceived poor health (scores I-4) } \\
\hline & & $\mathrm{N}$ & $\%$ & P-value \\
\hline Age & & & & $<0.01$ \\
\hline $\mathrm{I}-44$ & & 120 & 40.8 & \\
\hline $45-64$ & & 212 & 55.2 & \\
\hline 65- & & 135 & 38.5 & \\
\hline Gender & & & & $<0.001$ \\
\hline Men & & 169 & 36.1 & \\
\hline Women & & 298 & 52.8 & \\
\hline Working & & & & $<0.005$ \\
\hline Yes & & 205 & 41.2 & \\
\hline No & & 252 & 52.8 & \\
\hline Country of birth & & & & $<0.01$ \\
\hline Sweden & & 278 & 40.3 & \\
\hline Nordic & & 59 & 49.1 & \\
\hline Europe & & 58 & 67.2 & \\
\hline Other & & 72 & 52.8 & \\
\hline Living conditions & & & & $<0.05$ \\
\hline \multirow[t]{2}{*}{ Alone } & Yes & 128 & 57.8 & \\
\hline & No & 336 & 42.6 & \\
\hline \multirow[t]{2}{*}{ With other adult } & Yes & 318 & 41.5 & $<0.005$ \\
\hline & No & 146 & 58.2 & \\
\hline \multirow[t]{2}{*}{ With children $<18$} & Yes & 123 & 42.3 & NS \\
\hline & No & 341 & 48.1 & \\
\hline Healthy & & & & $<0.0000$ \\
\hline Yes & & 247 & 25.1 & \\
\hline Fair & & 26 & 69.2 & \\
\hline No & & 190 & 72.1 & \\
\hline Life satisfaction & & & & $<0.0001$ \\
\hline Low (score I-2) & & 45 & 88.9 & \\
\hline Fair (score 3-4) & & 128 & 78.9 & \\
\hline High (score 5-7) & & 292 & 25.7 & \\
\hline Population & & 470 & 46.4 & \\
\hline
\end{tabular}

* $\mathrm{N}$ not equal to 470 due to missing some values.

subjects who report that they are not healthy or less satisfied with life have PPH in comparison with healthy and satisfied subjects. Life satisfaction was strongly correlated to perceived health $(\mathrm{r}=0.66 ; \mathrm{p}<.0001)$.

Apart from BMI and smoking status, no other variable was significantly related to perceived health, table 2. Subjects who report PPH have higher BMI and smoke more than those with perceived good health. BMI is negatively related to PPH. The correlation for BMI and PPH is $(r=-$ $0.10 ; \mathrm{p}<.05)$.

\section{Symptoms and perceived health}

Having any of the 13 of 15 symptoms listed in the PQ was significantly related to PPH, i.e. those who report any of these symptoms more often have PPH than do non-symptomatic subjects. For some of these symptoms the risk is almost doubled or tripled, Table 3. For example, $87 \%$ of those reporting fainting spells have $\mathrm{PPH}$ compared to $44.4 \%$ among non-symptomatic subjects. The figures for feeling tired or having low energy and trouble sleeping were 62.6 and $62.9 \%$ as compared to 26.2 and $33.6 \%$ respectively.

\section{Chronic disease or conditions and perceived health}

Subjects who report having any chronic disease or condition report to a higher extent having PPH, table 4. In general about $50 \%$ of subjects with chronic disease report PPH as compared to $26.3 \%$ among non-diseased subjects. Having any of nine of these diseases or conditions was related to $\mathrm{PPH}$, heart failure, asthma, neurological disease, musculoskeletal and joint disorders, pain syndrome, psychiatric disorders, gastrointestinal and urinary tract troubles. For example, about $80 \%$ of subjects with a 
Table 2: Population distribution in per cent (\%) by perceived health and health status measures. Values are means unless otherwise indicated. Poor perceived health $(N=218)$, $\operatorname{good}(N=250)$.

\begin{tabular}{|c|c|c|c|c|c|}
\hline \multirow[b]{2}{*}{ Variables } & & \multicolumn{4}{|c|}{ Perceived health } \\
\hline & & Number & Poor (scores I-4) & Good (scores 5-7) & P-value \\
\hline Body Mass Index (BMI)* & & & 28.3 & 27.3 & $<0.05$ \\
\hline \multirow[t]{2}{*}{ Smoking } & Yes & 133 & 57.1 & 42.9 & $<0.005$ \\
\hline & No & 335 & 42.3 & 57.7 & \\
\hline \multicolumn{6}{|l|}{ Blood pressure } \\
\hline Systolic BP & & & 134.4 & 135.4 & NS \\
\hline Diastolic BP & & & 80.5 & 80.0 & NS \\
\hline Heart rate/minute & & & 70.7 & 68.8 & NS \\
\hline Blood glucose & & & 5.99 & 5.78 & NS \\
\hline Serum triglycyrids & & & 1.54 & 1.50 & NS \\
\hline Serum cholesterol & & & 5.46 & 5.28 & NS \\
\hline \multicolumn{6}{|l|}{ Spirometry } \\
\hline Vital capacity (VC) & & & 96.5 & 93.8 & NS \\
\hline Forced expiratory volume (FEVI) & & & 92.6 & 93.9 & NS \\
\hline Forced vital capacity (FVC) & & & 91.8 & 91.3 & NS \\
\hline PEF & & & 89.3 & 91.8 & NS \\
\hline Electrocardiography** & & & & & NS \\
\hline Normal & & 72 & 52.8 & 46.2 & \\
\hline Not sure pathological & & 49 & 36.7 & 63.3 & \\
\hline Suspect pathologic & & 226 & 43.8 & 56.2 & \\
\hline Pathological & & 111 & 52.3 & 47.8 & \\
\hline
\end{tabular}

$* \mathrm{BMI}=$ Weigh/length $\left(\mathrm{m}^{2}\right)$

*** Per cent

Table 3: The number of subjects with/without symptoms and the percentage (\%) of these reporting perceived poor health (PPH).

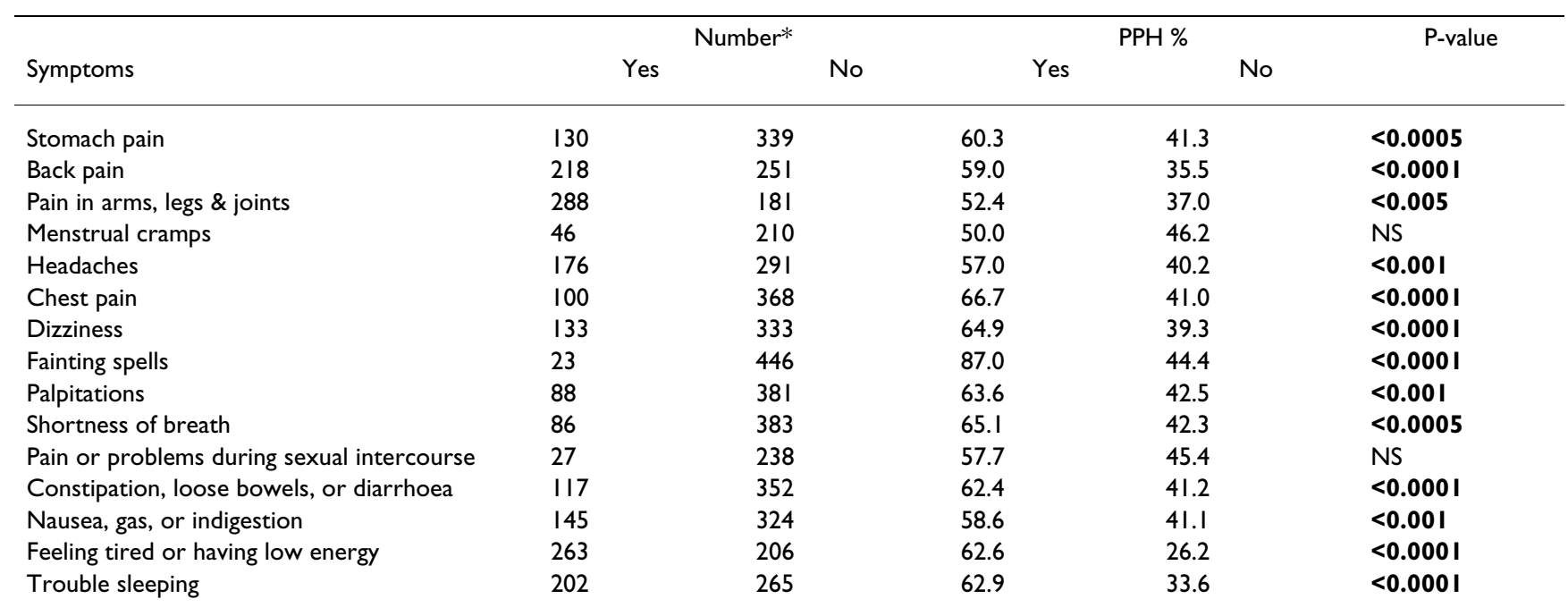

\footnotetext{
$* \mathrm{~N}$ not equal to 470 due to missing some values.
} 
Table 4: The number of subjects with/without a disease or a condition and the percentage (\%) of these reporting perceived poor health (PPH).

\begin{tabular}{|c|c|c|c|c|c|}
\hline \multirow[b]{2}{*}{ Disease or condition } & \multicolumn{3}{|c|}{ Number* } & \multicolumn{2}{|c|}{$\mathrm{PPH} \%$} \\
\hline & & & & & P-value \\
\hline Chronic disease & 394 & 76 & 50.3 & 28.5 & $<0.005$ \\
\hline Blood pressure & 84 & 354 & 49.6 & 45.8 & NS \\
\hline Angina & 38 & 429 & 52.6 & 46.1 & NS \\
\hline Heart failure & 15 & 452 & 73.3 & 45.8 & $<0.01$ \\
\hline Diabetes & 44 & 422 & 54.5 & 45.7 & NS \\
\hline Asthma & 59 & 408 & 67.8 & 43.6 & $<0.005$ \\
\hline Chronic obstructive disease & 13 & 454 & 38.5 & 46.9 & NS \\
\hline Neurological disease & 25 & 441 & 68.0 & 45.6 & $<0.0005$ \\
\hline Musculoskeletal disease & 89 & 378 & 68.5 & 41.5 & $<0.0001$ \\
\hline Joint disease & 255 & 212 & 55.3 & 36.3 & $<0.0005$ \\
\hline Pain syndrome & 112 & 355 & 65.1 & 39.4 & $<0.0001$ \\
\hline Cancer & 18 & 448 & 44.4 & 46.9 & NS \\
\hline Psychiatric disorder & 40 & 427 & 80.0 & 43.6 & $<0.0001$ \\
\hline Eye disease & 65 & 402 & 53.8 & 45.5 & NS \\
\hline Ear disease & 39 & 427 & 46.1 & 46.8 & NS \\
\hline Gastrointestinal disorders & 120 & 347 & 59.2 & 42.4 & $<0.0005$ \\
\hline Urinary tract disease & 59 & 406 & 55.9 & 45.1 & $<0.05$ \\
\hline
\end{tabular}

$* N$ not equal to 470 due to missing some values.

Table 5: The number of subjects with/without a psychiatric diagnoses and the percentage (\%) of these reporting perceived poor health (PPH). Perceived poor health $(N=218)$, good $(N=250)$.

\begin{tabular}{|c|c|c|c|c|c|}
\hline \multirow[b]{2}{*}{ Diagnose } & \multicolumn{2}{|c|}{ Number } & \multicolumn{2}{|c|}{$\% \mathrm{PPH}$} & \multirow[b]{2}{*}{ P-value } \\
\hline & & & & & \\
\hline Depressive disorders & 216 & 249 & 73.8 & 34.6 & $<0.0001$ \\
\hline Anxiety & 216 & 380 & 76.5 & 39.7 & $<0.0001$ \\
\hline Compulsive disorders & 23 & 441 & 76.5 & 44.4 & 0.0001 \\
\hline Social phobia & 10 & 455 & 60.0 & 46.2 & NS \\
\hline Probable alcohol abuse/dependent & 32 & 433 & 46.9 & 46.4 & NS \\
\hline Eating disorders & 11 & 454 & 54.5 & 46.3 & NS \\
\hline
\end{tabular}

psychiatric diagnosis report $\mathrm{PPH}$ and for heart failure the figure is $73.3 \%$.

From table 5 is obvious that depression, anxiety and compulsive disorders are related to $\mathrm{PPH}$. About $75 \%$ of subjects with one of these three disorders report PPH.

\section{Logistic regression analyses}

Table 6 shows odds ratios (OR) with 95\% confidence intervals (95\% CI) for having poor health by age, gender, living and working status, country of birth, smoking, chronic disease, depression, number of symptoms and life satisfaction. The ORs are adjusted for all confounders. We analysed the relationships between perceived health and the explanatory variables, using the unconditional logistic regression in successive models, adjusted for age and gender in the first model. This shows that subjects aged 4564 years have higher OR than older subjects, i.e. aged 65 or older. The OR was 1.62. The figure for males was 0.52 compared to females.

In the second model, when living conditions and country of birth were added to the analysis, the OR for subjects aged 45-64 years and for males remained significant. The ORs for subjects not living alone, working subjects and those born in Sweden were lower than for those living alone, not working and born outside Europe.

In the third model, with the addition of smoking status, chronic disease, depression and number of symptoms, the 
Table 6: Odds rations $(\mathrm{OR})$ with $95 \%$ confidence intervals $(95 \% \mathrm{Cl})$ for having poor health by age, gender, living and working status, country of birth, smoking, chronic disease, depression, number of symptoms and life satisfaction. The ORs are adjusted for all confounders.

\begin{tabular}{|c|c|c|c|c|c|c|c|c|c|}
\hline & & \multicolumn{8}{|c|}{ Perceived poor health (scores I-4) } \\
\hline & & \multicolumn{2}{|c|}{ Model I } & \multicolumn{2}{|c|}{ Model 2} & \multicolumn{2}{|c|}{ Model 3} & \multicolumn{2}{|c|}{ Model 4} \\
\hline & & OR & $95 \% \mathrm{Cl}$ & OR & $95 \% \mathrm{Cl}$ & OR & $95 \% \mathrm{Cl}$ & OR & $95 \% \mathrm{Cl}$ \\
\hline \multirow[t]{2}{*}{ Age $(65+$ years $=$ reference $)$} & $16-44$ & 0.96 & $0.59-1.57$ & 1.51 & $0.83-2.76$ & 0.65 & $0.31-1.33$ & 0.65 & $0.29-1.45$ \\
\hline & $45-64$ & 1.62 & $1.05-2.50$ & 2.47 & $1.45-4.21$ & 1.73 & $0.95-3.18$ & 1.44 & $0.74-2.81$ \\
\hline Male $($ female $=$ ref $)$ & & 0.52 & $0.35-0.76$ & 0.56 & $0,37-0.84$ & 0.86 & $0.54-1.37$ & 0.87 & $0.52-1.46$ \\
\hline Living alone (no = ref) & & & & 0.52 & $0.33-0.83$ & 0.67 & $0.40-1.11$ & 0.74 & $0.42-1.30$ \\
\hline Working (yes =ref) & & & & 2.10 & $1.35-3.26$ & 1.42 & $0.86-2.34$ & 1.21 & $0.69-2.11$ \\
\hline \multirow[t]{3}{*}{ Country of birth (other = ref) } & Sweden & & & 0.50 & $0.28-0.88$ & 0.52 & $0.26-1.02$ & 0.41 & $0.20-0.84$ \\
\hline & Nordic & & & 0.57 & $0.27-1.21$ & 0.44 & $0.19-1.02$ & 0.26 & $0.10-0.66$ \\
\hline & Europe & & & 1.19 & $0.55-2.57$ & 0.96 & $0.40-2.31$ & 0.68 & $0.26-1.80$ \\
\hline Smoking (yes $=$ ref) & & & & & & 0.81 & $0.50-1.32$ & 0.97 & $0.56-1.66$ \\
\hline Chronic disease (yes $=$ ref) & & & & & & 0.68 & $0.36-1.27$ & 0.97 & $0.56-1.27$ \\
\hline Depression $($ yes $=$ ref) & & & & & & 0.29 & $0.17-0.48$ & 0.55 & $0.31-0.98$ \\
\hline \multirow[t]{2}{*}{ Number of symptoms ( $>6$ ref) } & I-3 symptoms & & & & & 0.25 & $0.13-0.48$ & 0.30 & $0.15-0.60$ \\
\hline & 4-6 symptoms & & & & & 0.85 & $0.46-1.58$ & 0.98 & $0.50-1.92$ \\
\hline \multirow[t]{2}{*}{ Life satisfaction* (high = ref) } & Low & & & & & & & 15.40 & $5.28-44.97$ \\
\hline & Fair & & & & & & & 7.02 & $3.98-12.38$ \\
\hline
\end{tabular}

*Low (scores I-2), fair (scores 3-4) and high (scores 5-7)

** Interaction tests for chronic disease*depression, depression*symptoms and chronic disease*depression*symptoms were not significant.

pattern changed. Neither age nor gender was significant any longer. However, depression and number of symptom were significant. Non-depressed had OR $=0.29$ as compared to depressed. This means that depressed people have $71 \%$ higher risk than non-depressed of having PPH. The OR for having 1-3 symptoms and PPH was 0.25 as compared to those with more than 6 symptoms. The OR for those with 4-6 symptoms was 0.85 , as compared to those with more than 6 symptoms, but this is not significant. The linear trend is interesting. However, the OR for subjects born Sweden was still lower as than for those born outside Europe but the 95\% CI overlapped 1 (1.02), which was not significant.

In the final model (model 4) when all confounders were included, i.e. life satisfaction in addition to the previous variables, being born in Sweden or other Nordic countries was related to lower OR as compared to those born outside Europe. The OR for those born in Sweden was 0.41 and for those born in other Nordic countries 0.26 . The OR for non-depressed and those with 1-3 symptoms was somewhat higher but still significant.

The OR for low satisfaction with life was as high as 15.40 in comparison to those who are satisfied with life. However, the 95\% CI was very wide, 5.28-44.97. The OR for those who report fair life satisfaction is 7.02 and the $95 \% \mathrm{CI}$ is $3.98-13.38$.

\section{Discussion}

This study has shown that various socio-demographic characteristics and country of birth affect the subject's perceived health. A substantially high percentage reported that they had poor perceived health, with the lowest percentage in those born in Sweden. These figures were higher than the national Swedish average (5-6\%) and in other international reports $[41,42]$. However, Hjern et al. also found a higher prevalence of poor perceived health in subjects born outside Sweden [43]. Williams, in a study of women from the United States, found that socio-economic status was an important determinant of racial/ethnic disparities in health, but several other factors including, for example, medical care, migration, acculturation, stress and resources, also play a role [27]. Not surprisingly, perceived health was influenced by sociodemographic characteristics in this study, but it is noteworthy that another individual factor, "life satisfaction", showed a profile stronger than that of socio-demographic characteristics even after adjustment was made for age, gender, education, occupation, country of birth, chronic disease or condition and symptoms. This factor probably plays an important role in a subject's health and indicates the overall life satisfaction including health. The 
question about "life satisfaction" can also be used to assess health. Prospective studies are needed to confirm this. Indeed, this variable can probably be used together with perceived health, but needs to be investigated further. Many studies have shown the effect of age, gender, education, occupation and country of birth on health, which accord with our results $[44,45,5]$.

An interesting finding in this study is that patients aged 45-64 years have poorer health than older subjects. We believe that in this multi-ethnic population this age group is more vulnerable and sicker than the older subjects. It is possible that specific factors related to the neighbourhood in this study have an impact on health. Future studies should elucidate this issue. This could have important health policy implications. However, in the logistic model, the impact of age was not any longer significant when the symptom variable was taken into account.

As is the case with all questionnaire surveys, there was the possibility that patients exaggerated or underreported a condition, partly due to difficulties in remembering (recall bias). In addition to the potential problem of recall bias, there is the possibility of selection bias. The participants in this investigation were voluntary and time-limited, and we could only include those who showed interest first. It is possible that some selection bias occurred as a result of this consecutive procedure. It is possible, for instance, that our study included only the healthier patients in the Jordbro Health District because the sickest patients were not able to come to the health centre.

The questionnaire used in the present study (PRIME-MD) has been validated previously and shown to have good accuracy for psychiatric disorders [51-53]. Also, different parts of the questionnaire used here were previously validated in other investigation $[35,36,49,51]$. We also tested the questionnaire as a whole in advance in a pilot study and judged it to be satisfactory.

Although this study is not prospective, causal relations cannot be drawn from this investigation. The most of the literature on this issue are cross-sectional studies and not suited for statement or implications. Further prospective research is needed to clarify the direction of association. The new finding in this study is the strong association between life satisfaction and perceived health apart from country of birth, symptoms and depression, and also the fact that perceived health has a stronger correlation with psychiatric than somatic conditions. The strength of this study is that this represents a primary care patient population which makes it unique. Furthermore, the fact that we have controlled for a large number of confounders makes it more unique.
In conclusion, country of birth, depression, number of symptoms and life satisfaction are factors related significantly and independently to perceived health. Life satisfaction was the strongest predictor of poor health.

\section{Abbreviations}

OR = Odds ratio

95\% CI = 95\% Confidence Interval

Prime-MD = Primary Care Evaluation of Mental Disorders

$\mathrm{PQ}=$ Patient questionnaire

JHC = Jordbro Health Care Centre

$\mathrm{VC}=$ Vital capacity

FEV1 = Forced vital capacity during one second

PEF $=$ Peak expiratory flow

$\mathrm{PPH}=$ poor perceived health

$r=$ Spearman's correlation coefficient

$\mathrm{BMI}=$ body mass index

\section{Acknowledgements}

This study was supported by grants from Stockholm County Council (Dagmar \& ALF Fund) and Haninge Community Council (Economic Target to Large Cities).

\section{References}

I. Kaplan GA, Camacho T: Perceived health and mortality: a nineyear follow-up of the Human Population Laboratory cohort. Am J Epidemiol 1983, I I 7:292-304.

2. Sundquist J, Johansson SE: Self-reported poor health and low educational level predictors for mortality: a populationbased follow-up study of 39,156 people in Sweden. J Epidemiol Community Health 1997, 5 I:35-40.

3. Milunpalo S, Vuori I, Oja P, Pasanen M, Urponen H: Self-rated health status as a health measure: the predictive value of self-reported health status on the use of physician services and on mortality in the working-age population. J Clin Epidemiol 1997, 50:517-528.

4. Idler EL, Angel RJ: Self-rated health and mortality in the NHANES-I epidemiologic follow-up study. Am J Public Health 1990, 80:446-452.

5. Kaplan G, Barell V, Lusky A: Subjective state of health and survival in elderly adults. J Gerontol I988, 43:SI I4-I 20.

6. Idler EL, Benyamini Y: Self-rated health and mortality: a review of twenty-seven community studies. J Health Soc Behav 1997, 38:2I-37.

7. Benyamini Y, Idler EL: Community studies reporting associations between self-rated health and mortality. Research in Aging |999, 2 |:393-401.

8. Heistaro S, Jousilahti P, Lahelma E, Vartiainen E, Puska P: Self-rated health and mortality: a long-term prospective study in eastern Finland. J Epidemiol Community Health 200I, 55:227-232.

9. Angel R, Gronfein W: The use of subjective information in statistical models. ASR 1988, 53:464-473. 
10. Wannamethee G, Shaper AG: Self-assessment of health status and mortality in middle-aged British men. Int J Epidemiol 1991, 20:239-245.

II. Ferraro KF, Farmer MM, Wybraniec JA: Health trajectories: Long-term dynamics among black and white adults. J Health and Soc Behav 1997, 38:38-54

12. Al-Windi A, Elmfeldt $D$, Svärdsudd $K$ : The influence of sociodemographic characteristics on health care utilisation in a Swedish municipality. Ups J Med Sci 2004, 1 09:33-42.

13. Idler EL, Kasl S: Self-ratings of health: Do they also predict change in functional ability? J Gerontol B Psychol Sci Soc Sci 1995 50B:S344-353.

14. Al-Windi A, Elmfeldt D, Svärdsudd K: The influence of perceived well-being and reported symptoms on health care utilization: A population-based study. J Clinical Epidemiol 2002 55:60-66.

15. Connelly JE, Smith GR, Philbrick JT, Kaiser DL: Healthy patients who perceive poor health and their use of primary care services. J Gen Intern Med 1991, 6:47-5I.

16. Kjoller M, Rasmussen NK, Keiding LM: Self-reported health and morbidity among adult Danes 1987-1994. Ugeskr Laeger 1999, | 6 | :2948-2954.

17. Borgquist L, Hansson L, Nettelbladt P, Nordstrom G, Lindelow G: Perceived health and high consumers of care. a study of mental health problems in a Swedish primary health care district. Psychol Med 1993, 23:763-770.

18. Sihvonen AP, Kunst AE, Lahelma E, Valkonen T, Mackenbach JP: Socioeconomic inequalities in health expectancy in Finland and Norway in the late 1980s. Soc Sci Med 1998, 47:303-3I5.

19. Hallqvist J, Lundberg M, Diderichsen F, Ahlbom A: Socioeconomic differences in risk of myocardial infarction 197|-1994 in Sweden: Time trends, relative risks and population-attributable risk. Int J Epidemiol 1998, 27:410-4I5.

20. Cavelaars AE, Kunst AE, Geurts J], Helmert U, Lundberg O, Mielck A, Matheson J, Mizrahi A, Mizrahi A, Rasmussen N, Spuhler T, Mackenbach JP: Morbidity differences by occupational class among men in seven European countries: an application of the Erikson-Goldthorpe social class scheme. Int J Epidemiol 1998, 27:222-230.

21. Devlin N, Hansen $P$, Herbinson P: Variations in self-reported health status: results from a New Zealand survey. $N Z$ Med J 2000, I I 3:5 17-520.

22. Morris JK, Cook DG, Walker M, Shaper AG: Non-consulters and high consulters in general practice: cardio-respiratory health and risk factors. I Public Health Med 1992, I 4: I3 |- I 37.

23. Marmot MG, Adelstein AM, Bulusu L: Immigrant mortality in England and Wales 1970-78. Causes of death by country of birth. Studies on Medical and Population Subjects No. 47. London: OPCS; Her Majesty's Stationery Office; 1984.

24. Nazroo JY: Genetic, cultural or socio-economic vulnerability? Explaining ethnic inequalities in health. In The sociology of health inequalities Edited by: Bartley MB, Blane D, Davey Smith G. Oxford: Blackwell Publishers; 1998.

25. McGee DL, Liao Y, Cao G, Cooper RS: Self-reported health and mortality in a multiethnic US cohort. Am J Epidemiol 1999, 149:41-46.

26. Harding S, Maxwell R: Differences in the mortality of migrants. In F. Drever, M Whitehead, Health inequalities. London Stationery Office; 1997.

27. Williams DR: Racial/ethnic variations in women's health: the social embeddedness of health. Am J Public Health 2002, 92:588-597.

28. Nazroo JY: The health of Britain's ethnic minorities. London: Policy Studies Institute; 1997.

29. Sundquist J: Ethnicity, social class and health. A populationbased study on the influence of social factors on selfreported illness in 223 Latin American refugees, 333 Finnish and I 26 southern European labour migrants and 84 I Swedish controls. Soc Sci Med 1995, 40:777-787.

30. Kwok RK, Yankaskas BC: The use of census data for determining race and education as SES Indicators: $A$ validation study. AEP 2001, I I:I71-177.

31. Palmore $E$, Kivett $V$ : Change in life satisfaction: a longitudinal study of persons aged 46-70. J Gerontol I977, 32:31 I-316.
32. Wang CW, Iwaya T, Kumano H, Suzukamo Y, Tobimatsu Y, Fukudo S: Relationship of health status and social support to the life satisfaction of older adults. Tohoku J Exp Med 2002, I 98: I4I-I49.

33. Benyamini $Y$, Leventhal H, Leventhal EA: Self-rated oral health as an independent predictor of self-rated general health, selfesteem and life satisfaction. Soc Sci Med 2004, 59: I I09-I I I 6.

34. Ho SC, Woo J, Lau J, Chan SG, Yuen YK, Chan YK, Chi I: Life satisfaction and associated factors in older Hong Kong Chinese. J Am Geriatr Soc 1995, 43:252-255.

35. Al-Windi A: Depression in general practice. Nord J Psychiatry in press.

36. Tibblin G, Peciva S, Kullman S, Svardsudd K: "The Gothenburg quality of life instrument": An assessment of well-being and symptoms among men born 1913 and 1923. Methods and validity. Scand J Prim Health Care 1990, I:33-38.

37. Loerch B, Szegedi A, Kohnen R, Benkert O: The Primary Care Evaluation of Mental Disorders (PRIME-DM) German version: a comparison with CIDI. J Psychiat Res 2000, 34:2I I-220.

38. American Psychiatric Association. Diagnostic and statistical manual of mental disorders. 4th edition. Author, Washington, DC; 1994.

39. SAS: Introductory Guide; ed 3.I. Campus Drive, SAS Institute 3.I ed Cary 1997.

40. JMP-program:. Statistical Discovery Software. Introductory Guide, Version 4. SAS Institute Inc., Cary, NC, USA 2000.

4I. Statistics: Livslängd, hälsa och sysselsättning (Length of life, health and occupation). Stockholm, Sweden, Statististka centralbyrån (Statistics Sweden) 2002

42. Markovic M, Manderson L, Kelaher M: The health of immigrant women: Queensland women from the former Yugoslavia. J Immigrant Health 2002, 4:5-I5.

43. Hjern $A$, Haglund $B$, Persson $G$, Rosen $M$ : Is there equity in access to health services for ethnic minorities in Sweden? Eur J Public Health 2001, II:147-152.

44. Eriksson I, Undén A-L, Elofsson S: Self-rated health. Comparisons between three different measures. Results from a population study. Int I Epidemiol 200I, 30:326-33.

45. Verbrugge LM: Sex differences in health. Prevention 1982, 97:417-437.

46. Gijsbers van Wijk CM, Kolk AM: Sex differences in perceived health. Ned Tijdschr Geneeskd 1997, I41:283-287.

47. Joung IM, van der Meer JB, Mackenbach JP: Marital status and health care utilization. Int J Epidemiol 1995, 24:569-575.

48. Fylkenes K: Determinants of health care utilisation: Visits and referrals. Scand / Soc Med 1993, $21: 40-50$.

49. Al-Windi A: Determinants of Health Care and Drug Utilisation: The Causes of Health Care Utilisation Study. Uppsala, Uppsala University, PhD Thesis 2000.

50. Bosworth HB, Butterfield MI, Stechuchak KM, Bastian LA: The relationship between self-rated health care service use among women veterans in a primary care clinic. Women's Health Issues 2000, 1 0:278-285.

5I. Parker T, May PA, Maviglia MA, Petrakis S, Sunde S, Gloyd SV: PRIME-MD: its utility in detecting mental disorders in American Indians. Intl J Psychiat Med 1997, 27:107-I 28.

52. Kobak KA, Taylor LH, Dottl SL, Greist JH, Jefferson JW, Burroughs D, Mantle JM, Katzelnick DJ, Norton R, Henk HJ, Serlin RC: A computer-administered telephone interview to identify mental disorders. JAMA 1997, 278:905-910. 